\title{
Livros didáticos de Língua Portuguesa e identidades étnico-raciais
}

\section{Portuguese language textbooks and ethnic and racial identities}

Isabela Bastos de Carvalho, Mestranda, CEFET-RJ / IFF, isabascarva@gmail.com Alexandre de Carvalho Castro, Doutor, CEFET-RJ, o.aken@uol.com.br

\section{Resumo}

Este trabalho investigou identidades étnico-raciais aludidas pelos livros didáticos. Utilizando Bakhtin, analisamos alguns discursos de livros aprovados na última avaliação do PNLD. Os resultados da pesquisa evidenciaram materiais pouco dialógicos, reforçadores da branquitude. A pesquisa demonstrou reducionismo implicado no cânon literário indicado aos alunos e apontou para reforço de estereótipos.

Palavras Chave: Bakhtin, Língua Portuguesa, Relações étnico-raciais.

\section{Abstract}

This study investigated ethnic and racial identities suggested by textbooks. Based on Bakhtin's theory, we analyzed the discourses in books approved by PNLD. The research results showed inadequate teaching materials, as they were not very dialogical and they reinforced white supremacy. This research found an implied reductionism in the literary canon and an emphasis on stereotypes.

Keywords: Bakhtin, Portuguese language, ethnic and racial identities. 


\section{Introdução}

No campo de pesquisa sobre Língua Portuguesa (LP), há vários estudos que traçam um panorama histórico extenso do ensino dessa língua desde tempos idos até a atualidade. Algumas abordagens, contudo, apresentam interessantes singularidades. Nesse quadro geral, há estudos sobre Parâmetros Curriculares Nacionais (PCN) que são igualmente importantes, sobretudo os que, pautados numa perspectiva dialógica, não reduzem a análise à especificidade dos PCN, mas o fazem na relação com as práticas e os livros didáticos dessa disciplina (Almeida e Souza, 2011). O que se verifica, porém, é que a concepção de linguagem dos documentos oficiais não dialoga com o que prescrevem os livros didáticos (Silva, 2008; Silva, 2009; Silva e Cyranka, 2011).

Assim, uma vez que as práticas docentes e os materiais didáticos não estão em efetiva relação dialógica com os documentos oficiais (Custódio, 2010), e que há pouquíssima interação entre os livros didáticos de LP e os PCN (Monteiro, 2008), percebe-se a perpetuação de que o ensino desse componente curricular continua bastante tradicional. Até porque, mesmo com a existência do PNLD (Programa Nacional do Livro Didático), que filtra as obras didáticas e as avalia dentro de determinados critérios, o livro didático tem caráter ideológico e não deve ser a única ferramenta do professor (Almeida e Souza, 2011).

\section{Problema}

As diretrizes curriculares para o ensino médio se baseiam na Lei de Diretrizes e Bases da Educação Nacional (nº. 9394/96), no Parecer do Conselho Nacional da Educação/Câmara de Educação Básica no 15/98, e nos Parâmetros Curriculares Nacionais, que prescrevem uma série de práticas emancipadoras.

Os livros didáticos de Língua Portuguesa e Literatura, no entanto, são muito pouco dialógicos em relação aos PCN de LP do Ensino Médio. Isso se comprova quando se lê nesse documento oficial, entre outras informações importantes, que o ensino de Língua Portuguesa deve contribuir para o aluno construir sua própria identidade. Ora, se grande parte das escolas públicas investem na compra de livros didáticos, pressupõe-se que eles serão bastante utilizados nas aulas. E são. E apesar de haver, hoje, o filtro do PNLD, que seleciona as obras que podem ser adotadas nas escolas, os livros adotados descumprem as recomendações oficiais.

Percebendo que livros didáticos repetem determinadas práticas discursivas, este trabalho objetivou analisar, a partir do referencial teórico de Mikhail Bakhtin, quais identidades étnico-raciais são sócio-culturalmente construídas pelos livros didáticos de Língua Portuguesa e Literatura, utilizados no Ensino Médio. 


\section{Estratégias teórico-metodológicas}

Nesse cenário, a contribuição teórico-metodológica de Bakhtin, teórico russo que começa a escrever na década de 20 do século passado, precisa ser enfatizada. Isso porque ele dá especial atenção à questão do conceito de "enunciado", que emerge no contexto social imediato. Mais do que pela gramática, o enunciado concreto é marcado pela vida. Vale ressaltar que a comunicação eficaz deve ter início, meio e fim, e só pode acontecer porque os enunciados são estáveis - de modo muito semelhante, em situações semelhantes, repetem-se. Se a cada atividade humana um novo padrão de comunicação precisasse ser criado, talvez não houvesse comunicação verbal. O enunciado é, portanto, concreto, único, e é a própria materialização do pensamento, geralmente inserido em discursos, independentemente de aparecer em forma de uma oração, de uma composição de várias orações, de uma frase nominal, de um período ou mesmo de um texto complexo, desde que, em determinada situação enunciativa, tenha um sentido completo.

Para Bakhtin (1997), portanto, o discurso contém enunciados e cada enunciado possui sentido completo. É com o enunciado que língua e vida se conectam - "A língua penetra na vida através dos enunciados concretos que a realizam, e é também através dos enunciados concretos que a vida penetra na língua." (BAKHTIN, 1997, p.282). O enunciado é formado a partir de signos que, diferente da concepção dos gramatiqueiros ', podem sempre ser ressignificados, de acordo com a situação de enunciação. O sentido das palavras, portanto, é muito menos aquele dicionarizado, e muito mais aquele compartilhado pelos envolvidos em um determinado contexto comunicativo. E esse sentido é sempre construído historicamente na sociedade, seja em grandes grupos, ou mesmo no interior de pequenos grupos sociais para uso em determinadas situações, o que evidencia o dinamismo da língua portuguesa, que assume diferentes formas, em diferentes épocas.

Como acontecem no âmbito das atividades sociais, os enunciados estão intimamente relacionados às suas condições de produção. Essas condições são bem diferentes se compararmos os gêneros do discurso primários e os secundários. Tal distinção é conceituada por Bakhtin em um texto fragmentário escrito originalmente em 1952 / 1953, não revisto pelo autor, em que ele discute o que são enunciados, o que é discurso, e o que são os gêneros do discurso.

Em relação aos gêneros do discurso, os primários são muito mais simples e dinâmicos - em um diálogo, por exemplo, os participantes ouvem e falam e reelaboram o ouvido e o falado - as respostas são quase imediatas, e mesmo que não sejam faladas, são pensadas e podem ser percebidas. Esse tipo de gênero, no entanto, pode ser incorporado a gêneros mais complexos, os secundários (pode haver um diálogo em um romance, por exemplo). Nesse caso, o gênero primário 
perde sua interação envolta na realidade para a realidade específica do gênero secundário.

Assim, todo enunciado está - mesmo que isso não seja percebido conscientemente pelos usuários da língua - inserido em um gênero do discurso. Isto significa dizer que há uma certa performance que já é esperada nos atos comunicativos, nas atividades sociais, e essa performance é estabelecida pela especificidade de cada gênero do discurso, dotado de uma perceptível estabilidade.

É interessante perceber que apesar de muitos gêneros do discurso, primários e secundários, já existirem, não existem em número limitado, pois novos gêneros podem ser criados e cristalizados socialmente devido às mudanças sociais que ocorrem constantemente. De igual forma, certos gêneros também podem deixar de ser produzidos com o passar do tempo, como as cartas, que perdem sua força a cada dia. Além disso, segundo Bakhtin, os gêneros secundários são elaborados processualmente em um contexto sócio-histórico. Vale lembrar que todos os gêneros do discurso demandam uma compreensão responsiva ativa. Isso significa dizer que para todo enunciado haverá uma resposta, e mesmo que ela não seja conhecida por quem o produziu, o leitor/ouvinte certamente terá uma resposta, uma opinião, imediata ou não (quando não é imediata é uma compreensão responsiva de ação retardada, que geralmente ocorre a partir de gêneros secundários).

No processo de comunicação, todos os envolvidos participam ativamente, seja produzindo enunciados ou respondendo a eles, mesmo que seja em silêncio. E essa compreensão responsiva vai variar de acordo com o leitor/ouvinte: suas leituras, suas vivências, o contexto sócio-histórico em que está inserido etc. Assim, a linguagem é sempre dialógica: os discursos são sempre compostos por muitas vozes, pois o discurso alheio permeia sempre o nosso discurso.

Feitas essas considerações, pode-se considerar os livros didáticos de Língua Portuguesa usados nas escolas brasileiras como um enunciado inserido em um gênero do discurso secundário. Esses materiais ditam o que deve ou não ser ensinado a um determinado público. $\mathrm{E}$ o que se vê é um ensino formal da norma culta da língua, como se a língua existisse independentemente da vida. Há pouco espaço para a negociação e para o dialogismo nesse tipo de material. E exatamente porque esse ensino é pouco dialógico, prioriza a literatura canônica, como se outras literaturas não existissem, ou não merecessem destaque ". E uma possível resposta para isso pode ser pensada ao perceber que, diante de um material engessado, encontram-se alunos nada ativos, muito pouco responsivos. A resposta dos alunos até existe, mas é uma resposta que aparece em forma de reação, resistência, descaso, desinteresse.

Sendo assim, os livros didáticos de LP devem ser repensados, atualizados, de modo que todos os envolvidos no processo educacional, discentes e docentes, possam ter uma maior compreensão responsiva ativa, produtiva, interativa. Levando 
em conta um cenário educacional inadequado, novas propostas devem ser elaboradas: outros enunciados são possíveis.

Do ponto de vista metodológico, para demonstrar o engessamento do livro didático, que está focado no cânon e é delimitador de identidades sociais, três capítulos de três livros didáticos diferentes serão brevemente analisados, sendo um capítulo de cada livro. Vale ressaltar que todos os livros escolhidos foram aprovados pelo Programa Nacional do Livro Didático (PNLD), mais precisamente na última avaliação, e foram indicados nas escolas públicas de todo o Brasil para serem adotados de 2015 a 2017 no Ensino Médio. Os capítulos a serem analisados tratam do Simbolismo no Brasil, e a pretendida análise se restringirá ao que os livros dizem sobre o poeta Cruz e Sousa. Os livros escolhidos foram: "Ser protagonista", "Língua Portuguesa: linguagem e interação", e "Novas palavras". As referências completas constam das referências bibliográficas deste trabalho.

Antes de iniciarmos a análise, faz-se necessário justificar a escolha do poeta Cruz e Sousa (1861 / 1898). Trata-se de um poeta negro, filho de escravos alforriados, que foi, de certa maneira, adotado pela família que morava na casa onde seus pais trabalhavam. Teve, então, oportunidade de estudar e conhecer a literatura canônica europeia, que inspirava a brasileira. De modo muito inteligente, Cruz e Sousa utiliza a ferramenta do colonizador, a estética admirada na época e o português culto, até se pode dizer erudito, para demonstrar seu descontentamento relacionado à escravidão e ao racismo. Logo ele, um negro, um alguém que era considerado pertencente a uma raça inferior (teoria difundida e tida como científica no final do século XIX), consegue se destacar de maneira sublime dentre os poetas simbolistas brasileiros, tanto pela sua incrível qualidade artístico-literária, como pela maneira pela qual conseguiu abordar certos temas, que até então tentavam silenciar.

O primeiro livro, "Ser protagonista", utiliza duas páginas para falar sobre Cruz e Sousa. O título da seção do capítulo é "Cruz e Sousa: a tragédia da existência". Esse título não é explicado, e fala-se muito pouco da vida do poeta, tão rica e importante para compreender sua obra. Apenas menciona que sofria preconceito racial. Não há foto do poeta, e não há menção sobre suas lutas pelo fim da escravidão. Aparecem apenas duas de suas poesias - uma comentada (Braços), e a outra (O assinalado) com questões propostas para os alunos. Tais questões são superficiais e descontextualizadas, o que parece menosprezar a capacidade do aluno diante da complexidade dos textos simbolistas e evidencia que o capítulo explora mais os recursos estilísticos dos poemas. Um aluno negro, por exemplo, em vez de se sentir autoconfiante por termos na nossa literatura um poeta negro de tanto destaque, pode se sentir menosprezado, pois um dos únicos autores negros que compõe o cânon apresentado no livro ganha o título já exposto acima tragédia da existência. 
Em relação ao segundo livro, "Língua Portuguesa: linguagem e interação", aproximadamente quatro páginas exploram a obra de Cruz e Sousa. Aparecem duas poesias (Cristais e Violões que choram) - e um trecho em prosa poética (Ocaso no mar). Em pouquíssimas linhas, fala sobre a vida e a obra do autor, sem mencionar sua luta pelo fim da escravidão. Não há foto do poeta, apenas uma pequena caricatura. As questões propostas a partir dos textos não estimulam reflexão alguma, e ficam no plano puramente textual (como pedir que o aluno localize no texto determinada figura de linguagem ou analise as rimas do texto). O livro mescla literatura e língua portuguesa no capítulo. Na parte de língua portuguesa, apresenta frases de Cruz e Sousa de modo descontextualizado. Um exemplo que pode ser considerado até como ridicularização do poeta está na questão 6 da página 213, em que o aluno deve analisar conjunções que introduzem as orações subordinadas adverbiais temporais em frases como: "Antes que busque informações sobre o Simbolismo, leia Cruz e Sousa". As frases não estão inseridas em texto algum, e o nome do poeta Cruz e Sousa não faz sentido algum ali. Este livro, dentre todos os analisados, é o mais conservador. Apesar da proposta inovadora de unir língua, literatura e produção textual, não dá conta de nada disso. Pode-se dizer que presta um desserviço, pois ocupa o tempo do aluno e do professor para nada, ao passo que poderia problematizar o racismo e diversas outras questões sociais trazidas à tona por Cruz e Sousa.

Quanto ao terceiro e último livro, "Novas palavras", nove páginas falam de Cruz e Sousa. Muito diferente da abordagem dos outros livros analisados, o capítulo apresenta foto do poeta, sua história de vida e sua luta pelo fim da escravidão. Apresenta cinco poesias (Antífona, Hão de chorar por ela os cinamomos, Cárcere das almas, Afra, e uma sem título) e um trecho de texto em prosa poética (Dor negra). A maioria das questões é superficial, mas a densidade é bem maior se compararmos com os livros anteriormente analisados, e a questão da identidade étnico-racial é mais explorada. É um livro que nos deixa com alguma esperança de haver mais mudanças significativas nos materiais didáticos da contemporaneidade. Até porque, as informações / conteúdos, de modo geral, estão disponíveis online, e quase todas as escolas têm acesso à internet. Uma grande parte de alunos tem internet em casa! Assim, não basta o acesso à informação.

\section{Considerações finais}

Os resultados da pesquisa permitiram evidenciar materiais pouco dialógicos, que reforçam a branquitude. A pesquisa, além de demonstrar o reducionismo implicado no cânon literário indicado aos alunos, que praticamente exclui autores negros, aponta para uma não valorização da identidade negra e para o reforço de estereótipos.

Os livros didáticos deveriam estimular a leitura, a reflexão e a construção do pensamento crítico. Precisam situar o aluno no mundo e prepará-lo para ser um 
cidadão proativo. E colaborar na construção das múltiplas identidades que aparecem na sociedade hoje - os discentes precisam reconhecer sua identidade no livro com dignidade, independente de sua etnia, religião ou orientação sexual. E assim, o livro deve contribuir na formação de uma autoestima positiva, que, consequentemente, pode cooperar para a diminuição da evasão escolar e para a formação do gosto pelo conhecimento.

O livro, em vez de alienar alunos que não se veem representados nele, já que o cânon apresentado não conta com quase nenhum escritor negro, nem com mulheres, nem com indígenas etc, deveria fazer justamente o contrário. Deveria contribuir na valorização da diversidade, na construção de uma nação que possui múltiplas vozes e identidades sociais. Não deveria assujeitar os alunos à ideologia dominante. Nem deveria ser reificador do cânon, mantendo-o ali, intocável, protegido. O livro deveria, sim, romper preconceitos para que se possa enxergar outros caminhos possíveis, para permitir que a escola seja um espaço democrático do saber, onde todos têm vez, onde todos têm voz.

\section{Notas}

i. O termo gramatiqueiros é bastante recorrente no Brasil na área dos Estudos da linguagem e aparece em críticas de diversos autores, como BAGNO (2009) e POSSENTI (2009). Esse termo designa o profissional de Letras que se restringe ao ensino da gramática prescrita como "correta" ,"ideal", "superior", e que geralmente desconsideram (ou veem como inferior) outras possibilidades linguísticas.

ii. O conceito de cânon deve sempre ser problematizado. No momento em que determinadas obras passam a habitar o cânon, outras vozes são silenciadas e excluídas. "O cânon é um evento histórico, visto ser possível rastrear a sua construção e a sua disseminação. Não é suficiente repassá-lo ou revisá-lo, lendo outros e novos textos, não canônicos e não canonizados, substituindo os "maiores" pelos "menores", os escritores pelas escritoras, e assim por diante. Tampouco basta - ainda que isto seja extremamente necessário - dilatar o cânon e nele incorporar outras formações discursivas, como a telenovela, o cinema, o cordel, a propaganda, a música popular, os livros didáticos ou infantis, a ficção científica, buscando uma maior representatividade dos discursos culturais. O que é problemático, em síntese, é a própria existência de um cânon, de uma canonização que reduplica as relações injustas que compartimentam a sociedade" (REIS, 1992, p. 76).

\section{Referências Bibliográficas}

AMARAL, E. et al. Novas palavras: $2^{\circ}$ ano. 2 ed. São Paulo: FTD, 2013.

BAGNO, M. Não é errado falar assim - em defesa do português brasileiro. São Paulo: Parábola, 2009.

BAKHTIN, M. Os gêneros do discurso. In: Estética da criação verbal. $2^{a}$ ed. São Paulo: Martins Fontes, 1997. 


\section{SILID IV SIMAR \\ PUC-Rio - Dias 28, 29 e 30 de julho de 2015}

Marxismo e Filosofia da Linguagem. São Paulo: Hucitec, 1997.

Questões de estilística no ensino da língua. $1^{a}$ ed. São Paulo:

Editora 34, 2013.

BOSI, A. Poesia versus racismo. In: Literatura e resistência. São Paulo: Companhia das letras, 2002.

CRUZ E SOUSA, J. Obra Completa. Rio de Janeiro: Nova Aguilar, 2000.

FARACO, C.E. et al. Língua Portuguesa: linguagem e interação. 2 ed. São Paulo: Ática, 2013.

POSSENTI, S. Malcomportadas línguas. São Paulo: Parábola, 2009.

REIS, R. Cânon. In: JOBIM, J. L.(org.). Palavras da Crítica. Rio de Janeiro: Imago Ed., 1992.

Obra coletiva concebida por Edições SM. Ser protagonista: Língua Portuguesa, $2^{\circ}$ ano: ensino médio. 2 ed. São Paulo: Edições SM, 2013. 